\title{
ENTRE O PAROXISMO DE RAZÕES E A RAZÃO NENHUMA: PARADOXOS DE UMA PRÁTICA JURÍDICA ${ }^{1}$
}

\author{
Claudia Rosane Roesler ${ }^{2}$
}

\begin{abstract}
Resumo
Uma análise das decisões judiciais dos tribunais superiores brasileiros indica um acentuado déficit de racionalidade nas justificações produzidas pelos julgadores quanto às razões de suas decisões, se utilizados os instrumentos teóricos da Teoria da Argumentação Jurídica. Há uma notável dificuldade em se estabelecer claramente a vinculação entre a decisão tomada e suas razões, bem como em relacioná-la com outros elementos do ordenamento jurídico (normas gerais e padrões jurisprudenciais). Condicionamentos de caráter histórico e institucional podem servir como explicações plausíveis para este quadro e o presente artigo procura explorar, ainda que de modo inicial, algumas hipóteses explicativas da configuração da prática argumentativa brasileira.
\end{abstract}

Palavras-chave: argumentação judicial - tribunais superiores - teoria da argumentação jurídica - racionalidade

\section{INTRODUÇÃO}

Nos últimos anos temos assistido, de modo recorrente e a partir de diversas perspectivas teóricas, a um movimento de crítica à atividade judicante dos tribunais brasileiros. Ressalta-se, nesta crítica, a baixa qualidade técnica das decisões e a dificuldade de se visualizar uma linha coerente de fundamentação. A imagem geral é, assim, de um amontado de decisões, mais ou menos erráticas.

O presente artigo procura analisar a prática argumentativa dos tribunais superiores brasileiros, centrando-se no STF e no STJ, para compreender se essa crítica, por vezes feita de modo mais polêmico que academicamente orientado, pode ser amparada na prática argumentativa efetiva dos referidos tribunais. A análise, ao final, permite levantar algumas hipóteses explicativas e sugerir novos caminhos de pesquisa.

Para fins de análise, como se explicará em detalhes adiante, as decisões judiciais escolhidas foram tomadas pelo Supremo Tribunal Federal e pelo Superior Tribunal de Justiça. A hipótese de trabalho é, no entanto, mais ampla e abrange as características da argumentação realizada pelos demais tribunais superiores pois o seu objetivo principal é esboçar elementos que permitam compreender porque tais características aparecem.

\footnotetext{
${ }^{1}$ Resultado da análise realizada no projeto de pesquisa financiado pelo CNPq, intitulado "Argumentação Judicial e Controle Racional: o "estado da arte” da justificação das decisões judiciais nos tribunais superiores brasileiros”.

${ }^{2}$ Professora da Faculdade de Direito da Universidade de Brasília. Bolsista de Produtividade em Pesquisa do CNPq. E-mail: claudiaroesler@hotmail.com
} 
Evidentemente uma comprovação empírica da hipótese teria de ser providenciada para que a pesquisa pudesse afirmar conclusivamente que as características são comuns a todos os tribunais superiores.

A constatação mais geral, analisadas decisões recentes e relevantes, é a de que temos um argumentação abundante em muitos casos, absolutamente lacônica em outros que requereriam maiores cuidados de fundamentação, mas sempre uma dificuldade de determinar a relação entre os fundamentos elencados e a decisão tomada, tornando difícil o controle público e social da qualidade da decisão.

Paradoxalmente, no entanto, estas decisões, tão dificilmente submetidas ao controle social em razão de suas características, tem incidido de modo significativo sobre a garantia dos direitos humanos no Brasil, produzindo uma constatação interessante: por intermédio de uma cultura de decisão de contornos autoritários afirmam-se direitos.

O presente estudo reflete sobre esta situação, ainda que não explore todas as implicações decorrentes do paradoxo, e, para tanto, divide-se em duas partes. A primeira explora as características argumentativas de algumas decisões recentes dos tribunais superiores brasileiros e procura oferecer um retrato do que se pode constatar a partir de uma análise ancorada em instrumentos da teoria da argumentação jurídica. A segunda apresenta as hipóteses acima mencionadas e levanta alguns questionamentos capazes de inspirar estudos futuros.

\section{A ARGUMENTAÇÃO DOS TRIBUNAIS SUPERIORES E SUAS CARACTERÍSTICAS}

Para situar o leitor em relação aos pressupostos dos quais partimos é importante lembrar que o papel do Poder Judiciário na criação do Direito é um dos pontos centrais das teorias jurídicas contemporâneas e representa uma espécie de ponto de confluência entre as diversas perspectivas teóricas do fenômeno jurídico.

Um conjunto de elementos pode ser reconstruído para justificar nossa constatação. Certamente a centralidade da Constituição nos sistemas jurídicos contemporâneos e a abertura de sentido das normas jurídicas que decorre dessa centralidade são parte desta explicação. Articulada a ela, a superação de modelos teóricos baseados na concepção de validade formal das normas jurídicas, substituídos por modelos teóricos que enfatizam a dimensão argumentativa do Direito desempenha algum papel, assim como a crescente importância do Poder Judiciário na regulação social, como poder que não só dirime os conflitos individuais, mas também atua de modo significativo na resolução de conflitos entre os demais Poderes, entre os grupos sociais e entre a sociedade civil organizada e o Estado.

Não é desprezível, por outro lado, a dificuldade de, a partir de modelos de recrutamento e seleção pensados para o contexto de um Poder Judiciário mais técnico e menos político, encontrar soluções institucionais de controle da atividade judicial na contemporaneidade e, por fim mas não por último em importância, a 
necessidade de se utilizar elementos de controle racional das decisões judiciais, presentes nas suas justificações, para melhorar o controle social das decisões judiciais.

Mais do que uma questão teórica, no entanto, esta é uma relevante questão prática sobre a qual é preciso produzir conhecimento, já que se expressa em decisões importantes e definidoras da regulação social nos estados contemporâneos. Sua adequada percepção implica a realização de análises cuidadosas e empíricas de como a argumentação jurídica de fato se realiza em cada contexto nacional, pois, como se sabe desde os estudos de Retórica da Antiguidade, quem argumenta o faz dentro de uma prática argumentativa reconstruída constantemente pelos consensos presumidos ou refletidos dos participantes desta prática. Aquilo que é, portanto, aceito como racionalmente fundamentado ou passível de ser aceito como uma boa razão depende, ao menos em alguma medida, de uma inserção adequada no léxico de um auditório historicamente delimitado. Os participantes de uma prática argumentarão esgrimindo autores e ideias, manejarão certos tipos de argumentos e darão por pressupostos certos conceitos, conformando, ao final, um conteúdo e uma estrutura argumentativa peculiares, ainda que naturalizada e incorporada como o padrão a ser usado.

Neste sentido, cada ambiente argumentativo judicial constrói e naturaliza uma "forma de argumentar", que pode ser sinteticamente definida como o padrão formal utilizado na formulação e apresentação das decisões, abrangendo a sua apresentação em votos, a existência ou não de discussões e divergências consignadas nos acórdãos, o uso ou não de referências doutrinárias e jurisprudenciais, a presença de argumentos institucionais, materiais e formais. ${ }^{3}$

O presente artigo tem como pano de fundo essa constatação, mas, ao invés de prosseguir na válida e importante discussão teórica destes pontos, procura lançar luz sobre a prática argumentativa dos tribunais superiores brasileiros, compreendendo, como se disse acima, que para além das dimensões teóricas é preciso verificar como essa realidade se mostra em cada contexto institucional e como a prática jurídica em sua feição judicial incide na construção e na reconstrução dos direitos.

No intuito de buscar uma aproximação que permitisse compreender como essa problemática se traduz na prática argumentativa dos tribunais brasileiros foram realizadas análises de decisões recentes e relevantes tomadas pelo Supremo Tribunal Federal e pelo Superior Tribunal de Justiça. Optou-se por eleger um método de trabalho que consistiu em utilizar o esquema de Toulmin ${ }^{4}$ para a análise interna das decisões judiciais,

\footnotetext{
${ }^{3}$ Adota-se aqui a perspectiva resumida por Manuel Atienza em seu recente "Curso de Argumentación Jurídica”, no qual o autor, a partir de uma reconstrução das contribuições de Raz e Summers (dentre outros autores) classifica as razões para a justificação de uma decisão em razões materiais (que versam sobre o conteúdo mesmo da ação justificada, sua qualidade valorativa), razões formais ou autoritativas (como as decorrentes da afirmação de que decorrem de uma ordem dada por uma autoridade reconhecida pelo sistema) e as razões institucionais (aquelas que decorrem da divisão de competências ou de poderes entre diversos órgãos e que servem a justificar porque um curso de ação, embora desejável, pode não ser de competência de quem decide). Veja-se, especialmente o capítulo IV - La concepción material: premisas e razones. ATIENZA, 2013, p. 275-287.
}

${ }^{4}$ TOULMIN, 2006, passim. 
determinando a sua estrutura argumentativa, e os requisitos de uma decisão racional propostos por Neil MacCormick ${ }^{5}$ para a análise externa das decisões. A pesquisa abrangeu decisões tomadas pelo STF e pelo STJ nos últimos anos e foi realizada entre os anos de 2011 e 2013.

Para o ano de 2011 a decisão do STF selecionada versou sobre a aplicação da Lei de Anistia ${ }^{6}$. Em 2012 foram selecionadas as decisões do STF e do STJ sobre a periculosidade de pessoas acometidas de transtorno mental, e a análise versou sobre um total de 65 acórdãos (catorze acórdãos proferidos pelo Supremo Tribunal Federal e 51 pelo Superior Tribunal de Justiça) ${ }^{7}$. Além dessas, a decisão do STF sobre a "Lei da Ficha Limpa" foi examinada, tendo-se em vista a sua incidência sobre a construção dos direitos políticos ${ }^{8}$. Aprofundando a análise da decisão tomada pelo STF sobre a Lei de Anistia, produziu-se também uma reflexão sobre a dimensão de gênero no discurso do tribunal, procurando apreender se havia alguma sensibilidade para a especificidade da violência contras as mulheres ao longo do período coberto pela anistia concedida pela lei em questão?

Em 2013 e sob o ângulo do STJ a opção recaiu sobre a decisão que discutiu a aplicação da Lei Seca (Recurso Especial 1.111.566-DF) dada a sua relevância para a proteção dos direitos individuais ${ }^{10}$. Abrangendo as decisões de cortes estaduais e a decisão do STF, analisou-se também os acórdãos que reconheceram ou não a possibilidade da união homoafetiva. Foram analisados 186 acórdãos dos tribunais de justiça e a ADI $4.277^{11}$.

Os dados colhidos nessas análises, como se pode bem imaginar, são bastante férteis e multifacetados, exigindo uma reflexão mais profunda e meditada para que se possa esboçar um "resultado" definitivo e definidor do estado da arte da justificação dos tribunais superiores brasileiros. Alguns achados, no entanto, podem ser discutidos na perspectiva específica deste texto.

Em primeiro lugar, parece bastante evidente que as decisões tomadas pelo STF em casos controversos, como alguns dos analisados (União Homoafetiva ${ }^{12}$ e Lei de Anistia ${ }^{13}$ ) são veiculadas em acórdãos extensíssimos e, portanto, de difícil análise técnica. A argumentação realizada pelos ministros e ministras versa sobre um conjunto tão amplo e variado de pontos e usa de um conjunto igualmente amplo e variado de fontes que a mera separação dos fundamentos da decisão - as ratio decidendi - e os comentários ou acréscimos - obiter dicta - é

\footnotetext{
${ }^{5}$ MACCORMICK, 2008, .

${ }^{6}$ ROESLER; SENRA, 2012.

${ }^{7}$ ROESLER; LAGE, 2013.

${ }^{8}$ Cfe. MOREIRA, 2012.

${ }^{9}$ ROESLER; SENRA, 2013.

${ }^{10}$ CHAIM, 2013.

${ }^{11}$ Para os detalhes da análise, veja-se ROESLER; SANTOS, 2014.

${ }^{12}$ BRASIL. 2011. Supremo Tribunal Federal. Ação Direta de Inconstitucionalidade No 4277. Inteiro Teor do Acórdão. Relator: Min. Ayres Britto. Consulta em 05/04/2012. Disponível em: http://www.stf.jus.br/portal/geral/verPdfPaginado.asp?id=400547\&tipo=TP\&descricao=ADI\%2F4277

${ }^{13}$ BRASIL. 2010. Supremo Tribunal Federal. Argüiçã o de Descumprimento de Preceito Fundamental no. 153. Inteiro Teor do Acorda o. Relator: Min. Eros Grau. Consulta em 03/08/2011. Disponivel em:
} http://redir.stf.jus.br/paginadorpub/paginador.jsp?docTP=AC\&docID=612960. 
uma empreitada praticamente impossível. Acresce-se à extensão e à amplitude das referências a peculiar característica de que em algumas decisões não há claramente uma discussão entre os julgadores sobre os mesmos pontos. Uma síntese, portanto, dos fundamentos da decisão é uma tarefa dada ao intérprete e realizada com base em algum critério externo à decisão.

Nesse ponto específico, aliás, há indícios bastante significativos de que o STJ siga o mesmo padrão, como se pode ver, por exemplo, na análise realizada do julgamento do Recurso Especial que discutiu a aplicação da "Lei Seca", no qual os ministros claramente não discutem os mesmos pontos, dificultando sobremaneira a análise comparativa ou o resumo das razões de decidir da decisão. ${ }^{14}$

Pode-se constatar, também, que o sistema de decisão colegiada adotado no Brasil, de votos individuais preparados previamente pelos julgadores (e pelos seus assessores) com base no processo judicial e levados à sessão de julgamento sem que necessariamente haja um conhecimento prévio por parte dos demais sobre a opinião do relator ou de cada decisor contribui para essa dificuldade. Na maior parte dos casos percebe-se claramente um texto estruturado de antemão, produzido em gabinete, que ou não é modificado no momento da discussão em colegiado ou se o é, vem simplesmente acrescido de novos argumentos ou de uma reedição dos argumentos já elencados na parte principal do voto de cada julgador ${ }^{15}$.

Esta forma cria uma realidade que pode ser sinteticamente definida como um conjunto de decisões mais do que uma decisão colegiada, na qual se podem encontrar concordâncias e discordâncias não enfrentadas resultando em votações majoritárias ou decisões por unanimidade. Em outras palavras, embora a decisão seja colegiada, não é sempre e exatamente o produto de um debate realizado no colegiado, mas uma superposição de posições, que redundam em uma decisão, eventualmente com a concordância sobre os fundamentos, mas não necessariamente. ${ }^{16}$

\footnotetext{
${ }^{14}$ BRASIL. 2012. Superior Tribunal de Justiça. Recurso Especial no. 1.111.566/DF. Inteiro Teor do Acórdão. Relator: Min. Marco Aurélio Bellize. Acesso em 08/07/2013. Disponível em: https://ww2.stj.jus.br/processo/jsp/revista/abreDocumento.jsp?componente=ITA\&sequencial=1114564\&num_registro=2009 00250862\&data $=20120904 \&$ formato=PDF.

${ }^{15}$ A titulo de exemplo pode-se citar o voto do Ministro Gilmar Mendes no acórdão da ADI 4277, no qual se percebe que o Ministro inicia fazendo uma série de considerações e de referencias conceituais mais ou menos livres e posteriormente as repete de modo mais sistemático e organizado no texto da parte final de seu voto. Presume-se que a primeira parte foi produzida em plenário e a segunda já havia sido redigida quando do estudo do processo judicial em gabinete. BRASIL. 2011. Supremo Tribunal Federal. Ação Direta de Inconstitucionalidade No 4277. Inteiro Teor do Acórdão. Relator: Min. Ayres Britto. Consulta em 05/04/2012. Disponível em: http://www.stf.jus.br/portal/geral/verPdfPaginado.asp?id=400547\&tipo=TP\&descricao=ADI\%2F4277. Veja-se especialmente as páginas 728-751, nas quais o Ministro expõe em linhas gerais a sua opinião e cita diversos autores (Perelman, Haberle, Alexy) e posteriormente o voto recomeça, a partir da página 752, prosseguindo até a 806 e novamente citando os mesmos trechos, dos mesmo autores, na mesma linha de raciocínio já exposta nas paginas anteriores.

${ }^{16}$ Em alguns casos decididos pelos tribunais superiores usa-se a expressão "voto médio" para significar a posição alcançada após um debate no colegiado. Nestas ocasiōes escolhe-se um dos ministros da posição majoritária para redigir o voto e ele deve fazer uma síntese do acordo realizado em plenário. Um exemplo desse tipo de decisão e do seu registro em um acórdão pode ser encontrada na ADI 3105, julgada pelo STF em 2004.
} 
É evidente que esta realidade institucional - o sistema de votos individuais apresentados prontos ao colegiado e a subsequente incorporação de tudo o que é dito ao longo da sessão de julgamento no acórdão de inteiro teor - possibilitaria, em princípio e em tese, um maior controle da produção da decisão, eis que tudo fica registrado no texto final. O primeiro paradoxo aparece, aqui, na constatação de que este mecanismo de publicização extrema das razões de decidir de todos e de cada um dos julgadores envolvidos na decisão; acarreta exatamente a dificuldade de se compreender quais foram as razões de decidir.

O passo seguinte à decisão tomada em plenário e que corresponde à sua transformação em uma ementa que sintetiza a decisão tomada pelo colegiado, por seu turno, não necessariamente obedece à razoável pressuposição de que deve representar uma síntese de todos os posicionamentos definidores da decisão. Realizada normalmente pelo relator ou pelo julgador que liderou a maioria, não raramente representa apenas os fundamentos da sua opinião e não incorpora de modo compreensível e visível o exposto pelos demais que, não tão raramente, concordam quanto à decisão mas não quanto aos seus fundamentos.

É bastante evidente que uma reconstrução dos fundamentos de qualquer decisão judicial é uma tarefa a ser realizada a posteriori e de modo externo, ou seja, pelo intérprete. Em nenhum tribunal há uma clara identificação de quais são as ratio decidendi pelos próprios julgadores. É preocupante, no entanto, que a dificuldade seja tal que a razoável concordância entre intérpretes capazes tecnicamente e bem preparados nem sempre possa ser alcançada e isso diga respeito à decisões de grande impacto no ordenamento jurídico brasileiro, como, por exemplo, a decisão que reconheceu a união homoafetiva. Não se trata, como é intuitivo, de uma decisão corriqueira e nela fica clara a relevância da função judicial, sobretudo porque a sua assunção implicou uma interpretação bastante afastada da literalidade do texto constitucional ${ }^{17}$.

A soma desses fatores acarreta um diagnóstico bastante assustador cujo resumo poderia ser o seguinte: sabe-se dizer qual foi a decisão tomada, mas não necessariamente se consegue compreender quais as suas razões e, por vezes, qual o seu alcance ${ }^{18}$. Se considerarmos, como sói acontecer nos ordenamentos jurídicos contemporâneos, que a jurisprudência orienta ou vincula as decisões posteriores, seria razoável supor que o cuidado com a explicitação das razões fosse cada vez maior, eis que cresce significativamente o papel do Poder Judiciário como um verdadeiro regulador das condutas sociais, como se apontava no início desta reflexão.

Um outro ponto importante que se depreende na análise referida é a do uso da doutrina como apoio para a construção das decisões. Observa-se que há um uso abundante de referências a autores, nacionais e

\footnotetext{
${ }^{17} \mathrm{O}$ texto constitucional tem a seguinte redação:

"Art. 226. A família, base da sociedade, tem especial proteção do Estado. (...)

$\$ 3^{\circ}$ - Para efeito da proteção do Estado, é reconhecida a união estável entre o homem e a mulher como entidade familiar, devendo a lei facilitar sua conversão em casamento."

${ }^{18} \mathrm{Um}$ bom exemplo desta realidade pode ser a decisão da união homoafetiva, acima referenciada, sobre a qual pairam dúvidas se teria também autorizado a adoção por casais homoafetivos e que certamente terá de ser precisada pelo STF em um futuro próximo. vol. 08, nº. 04, Número Especial. Rio de Janeiro, 2015.pp. 2517-2531 
estrangeiros, frequentemente com um evidente caráter de apelo à autoridade, pois as citações ou menções feitas não são adequadamente discutidas e inseridas no contexto discursivo da decisão. Deve-se esclarecer que a adequada menção a conceitos teóricos pode ser até desejável e auxiliar na compreensão das razões pelas quais uma decisão foi tomada. Discutível, no entanto, é a enumeração sucessiva de autores cuja congruência é de difícil percepção. Um exemplo sintomático disso é o voto do relator na decisão que reconheceu a união homoafetiva, no qual, em 32 páginas, citam-se 14 autores distintos, que vão de Hans Kelsen a Carl Jung, passando por Chico Xavier e Caetano Veloso, Jean-Paul Sartre, Hegel e Nietzsche. O segundo voto dessa mesma decisão, em 11 páginas, cita 13 autores. $\mathrm{O}$ ministro que o exara afirma, ademais, que uma sentença é e deve ser "aquilo que o juiz sentiu, o sentimento do juízo" e em seguida faz, como expressamente afirma, uma "digressão" de cerca de 9 páginas para, ao final, assumir integralmente o voto do relator. Tal abundância de citações parece poder ser explicada como uma tentativa de construção de uma imagem de erudição para o prolator do voto, mais do que, como seria de se esperar num caso desta complexidade e envergadura, uma argumentação voltada ao entendimento de um espectador que precise ser convencido da correção das razões pelas quais a decisão está sendo tomada.

A análise das decisões nos permite verificar, ainda, que há pouco cuidado na aplicação da jurisprudência como um precedente que sirva à fundamentação da nova decisão tomada. Assim, nem sempre a posição anteriormente tomada pelo colegiado é mantida e por vezes não há nenhuma discussão mais cuidadosa das razões pelas quais a corte em questão muda o seu posicionamento. Em sentido similar, mas na direção oposta, os nossos julgadores parecem pensar que se há uma concordância com a linha jurisprudencial já firmada, o argumento definitivo é simplesmente referir-se à decisão anterior, sem argumentar sobre a sua pertinência ao novo caso, limitando-se a invocar a decisão sem apresentar nenhum tipo de explicitação de suas razões. Em síntese, parece possível afirmar que também aqui encontramos uma dificuldade razoável para compreender de que modo a jurisprudência funciona como um elemento de controle da racionalidade das decisões no contexto de uma afirmação do Poder Judiciário enquanto um importante foco de construção de direitos.

Nesse sentido, pareceu-nos extremamente grave e sintomática a posição do STJ observada por ocasião da análise ${ }^{19}$ que fizemos de suas decisões sobre a aplicação da medida de segurança com fundamento na periculosidade do agente ${ }^{20}$.

\footnotetext{
${ }^{19}$ ROESLER; LAGE, 2013.

${ }^{20}$ Realizou-se o levantamento e a análise de todos os acórdãos relativos ao assunto proferidos pelo Supremo Tribunal Federal (STF) e pelo Superior Tribunal de Justiça (STJ) que atendiam aos critérios escolhidos. A pesquisa jurisprudencial foi realizada nos sites dos respectivos tribunais, utilizando-se as palavras-chave "periculosidade" e "inimputabilidade" ou "semi-imputabilidade". Foi empregado um caractere que substitui parte das palavras, de modo que, em uma única pesquisa, pudessem ser encontrados resultados que utilizassem as palavras "inimputabilidade" ou "inimputável". Além disso, adotou-se como critério de delimitação temporal a partir do dia 13 de julho de 1984, data em que foram publicadas a Lei 7.209, que reformou a Parte Geral do Código Penal, e a Lei 7.210 (Lei das Execuções Penais), as quais compõem o núcleo da atual disciplina legal sobre inimputabilidade e vol. 08, nº 04, Número Especial. Rio de Janeiro, 2015.pp. 2517-2531 2523
} 
Nesta matéria, a jurisprudência do Supremo Tribunal Federal consolidou-se no sentido de que a duração máxima das medidas de segurança é trinta anos. No Superior Tribunal de Justiça, no entanto, existiam até recentemente três orientações diferentes sobre esse assunto:

1. Não há limite máximo de duração das medidas de segurança, cuja extinção é condicionada à cessação da periculosidade;

2. Esse limite é determinado pelo máximo da pena abstratamente cominada para a infração penal cometida;

3. A duração das medidas de segurança atém-se ao máximo de trinta anos.

A pesquisa mencionada mostrou que a maior parte dos julgados foi realizada por uma mesma Turma e, portanto, a mesma questão foi decidida por uma composição razoavelmente estável de decisores. ${ }^{21}$ Apesar disso, constata-se que não se tem promovido qualquer alteração jurisprudencial institucionalmente por meio de debates nos órgãos colegiados, mas por meio da mudança do entendimento individual de cada Ministro ${ }^{22}$.

Como é facilmente perceptível, as orientações encontradas no STJ são incompatíveis entre si e é particularmente grave perceber que todos os acórdãos do STJ analisados no estudo mencionado foram aprovados por unanimidade dos Ministros que compõem os órgãos fracionários do tribunal.

Esta análise merece algum detalhamento porque pode servir como um bom ponto de observação para o problema que estamos examinando. Realizada a verificação da estrutura argumentativa de cada um dos acórdãos selecionados, constatou-se a predominância dos argumentos de tipo dedutivo e da justificação interna ${ }^{23}$ das decisões. Além da aprovação por unanimidade dos magistrados que compõem os órgãos colegiados, os acórdãos não contém em si discussões sobre o ponto em que discordam, ou seja, a discordância não é tematizada no momento da tomada de decisão.

medidas de segurança, até o dia 15 de junho de 2012, data em que foi publicado o acórdão mais recente do STJ no momento da pesquisa jurisprudencial. Ao todo foram examinados catorze acórdãos do Supremo Tribunal Federal e 51 do Superior Tribunal de Justiça.

${ }^{21}$ No âmbito da pesquisa realizada, apenas o HC 142.672/RS, julgado em 10 de abril de 2010, o HC 70.497/SP, julgado em 12 de novembro de 2007, e o HC 27.993/SP, julgado em 09 de dezembro de 2003, foram distribuídos à Sexta Turma. Todas as demais decisões foram proferidas pela Quinta Turma.

${ }^{22}$ Levando em conta apenas a composição atual da Quinta e da Sexta Turma do STJ e os acórdãos incluídos nos critérios da pesquisa $^{22}$, os Ministros Jorge Mussi e Gilson Dipp afiliam-se à primeira orientação (inexistência de limite temporal). A Ministra Laurita Vaz, até fevereiro de 2008, também endossou essa opinião, mas em dois casos posteriores a setembro de 2009 seguiu a jurisprudência do STF. Igualmente, o Ministro Arnaldo Esteves Lima, que fazia parte da Quinta Turma e hoje preside a Primeira Turma (a qual não tem competência em matéria penal), parece ter mudado de posição: em um caso julgado em novembro de 2008, ele manifestou-se a favor da indeterminação da duração máxima das medidas de segurança, porém em dois outros julgados após outubro de 2009, entendeu que o limite deveria ser o máximo da pena cominada para a infração penal. Em seu voto no REsp 1.103.071/RS, o Min. Arnaldo Esteves Lima noticia que a Min. Maria Thereza de Assis Moura, da Sexta Turma, também adota essa posição.

${ }^{23}$ Denomina-se justificação interna aquela que correlaciona as premissas normativas e fáticas da decisão, dadas como assentadas, produzindo a conclusão que se expressa, posteriormente, na decisão propriamente dita. Opõe-se à justificação externa que é qualificada como aquela que versa sobre o estabelecimento de ambas ou de uma das premissas - normativa e fática - e requer o uso de uma variedade de técnicas argumentativas. Veja-se ATIENZA, 2002, p. 50-51. 
Aparentemente, portanto, nossos julgadores do STJ compreendem esses casos como "casos fáceis" ${ }^{\text {"24 }}$ nos quais não há que se justificar as premissas utilizadas de modo mais amplo, bastando mencioná-las e "aplicar a norma ao caso concreto". Mais do que isso, se há distintas orientações jurisprudenciais e os julgamentos são todos por unanimidade, parece razoável supor que os ministros seguem sempre o voto do relator, sem discutir o teor de suas posições, concebendo a sua tarefa como uma adesão à opinião expressa pelo colega.

Os problemas argumentativos encontrados nas decisões sobre essa matéria não terminam, no entanto aí. Alguns problemas argumentativos específicos foram identificados e discutidos em texto resultante da pesquisa ${ }^{25}$. Resumidamente e para fins de ilustração, observa-se, quanto à relação entre direito e psiquiatria nas decisões judiciais analisadas, que o silêncio dos tribunais sobre o problema da periculosidade pode ser interpretado como um déficit argumentativo, pois a própria noção de "periculosidade" mereceria alguma fundamentação para que a sua aplicação fizesse sentido no contexto de um ordenamento jurídico que protege a liberdade individual e a dignidade da pessoa humana.

Como esses problemas argumentativos podem claramente demonstrar, é chocante constatar que a liberdade e a vida dos submetidos ao controle do sistema penal são tratados sem nenhum cuidado argumentativo e os casos julgados, simplesmente assumidos como "casos fáceis", sem qualquer tipo de justificação externa que racionalmente permita discutir a qualidade das premissas utilizadas. $\mathrm{O}$ azar ou a sorte, entendidos em seu sentido mais amplo possível, desempenharão um papel relevante na decisão do destino do jurisdicionado: a depender do relator de seu pedido de habeas corpus, sua medida de segurança terá uma duração de 30 anos, de alguns anos ou durará até que a periculosidade cesse. Como a definição de periculosidade assumida nos laudos médicos é absolutamente ampla e genérica ${ }^{26}$, novamente a sorte ou o azar incidirão na constatação deste requisito da aplicação da medida de segurança.

Aparentemente estamos diante da situação exatamente contrária ao que verificamos no acórdão do julgamento da Lei de Anistia e da União Homoafetiva: ao invés de textos extensíssimos, com um excesso de

\footnotetext{
${ }^{24}$ São considerados "casos fáceis" neste contexto aqueles que não requerem justificação externa das premissas de decisão e teriam, portanto, um decurso argumentativo simplificado, no qual bastaria mencionar a premissa normativa, a premissa fática e de sua relação retirar a conclusão. A classificação de um caso como "fácil” ou "difícil” é, portanto, uma decisão operada previamente pelo intérprete/decisor que se move em um contexto argumentativo dado e conformado pelas normas jurídicas constitucionais, legais e jurisprudenciais. Os casos, portanto, não são "fáceis" ou "difíceis" mas devem ser enquadrados como tais em uma tradição argumentativa e em um dado momento desta.

${ }^{25}$ ROESLER; LAGE, 2013.

${ }^{26}$ Use-se como exemplo os indicadores de periculosidade adotados pelo Instituto Médico-Legal (IML) do Distrito Federal: "Quanto à curva vital: inconstância no trabalho, integração com grupos sem atividades construtivas, existência de criminalidade precoce, número elevado de incidentes jurídicos e policiais, reincidência rápida, início precoce da doença. - Quanto à morfologia do crime: crime praticado com agravantes legais, crime sem motivo psicológico explicável, crimes com multiplicidade de golpes, crimes praticados com frieza de sentimentos, crimes praticados contra pessoas indefesas. - Quanto a intercorrências psiquiátricas: agitação psicomotora, surtos e episódios psicóticos, crimes de irrascibilidade, necessidade de altas dosagens de fármacos. - Quanto ao exame psíquico atual: humor explosivo, falta de crítica ao ato delituoso que praticou, falta de planos para o futuro, alucinações, delírios, falta de remorso, falta de sentimentos superiores, egocentração dos sentimentos. É importante também que seja avaliada a ligação do examinando com a família e o desejo e o interesse de conviver com a mesma." Apud BRAVO, 2004, p. 129.
} vol. 08, nº. 04, Número Especial. Rio de Janeiro, 2015.pp. 2517-2531 
razões sendo esgrimidas, autores sendo citados e decisões anteriores mencionadas (ainda que sem o devido acabamento argumentativo) há aqui um silêncio eloquente que permite ao tribunal evitar o debate entre as posições, assumindo como "natural" que cada um dos julgadores tenha a sua opinião a respeito do tema, mas também que não é necessário que um acordo seja produzido. O "acordo", aqui, é "cada um respeitar a opinião do outro", de modo a possibilitar as decisões por unanimidade.

Realizada a análise das características das decisões, passemos às reflexões sobre esta prática argumentativa.

\section{DE MUITAS RAZÕES A RAZÃO NENHUMA: O PARADOXO DA ARGUMENTAÇÃO JUDICIAL DOS TRIBUNAIS BRASILEIROS}

Como se constatou no item anterior deste texto, aparentemente os tribunais superiores brasileiros, especialmente o Supremo Tribunal Federal e o Superior Tribunal de Justiça, argumentam de modo diferenciado segundo o caso seja "fácil" ou "difícil”. Naqueles considerados casos “fáceis" não há uma argumentação explicitada e os decisores limitam-se a invocar normas legais e precedentes jurisprudenciais, dando por pressuposta a correção de sua aplicação ao caso que está sendo julgado. Naqueles considerados "difíceis", ao contrário, há uma grande exposição de elementos e razões expostos para a fundamentação da decisão.

Paradoxalmente, no entanto, como vimos no caso das medidas de segurança, não há uma argumentação detalhada e abrangente, justificadora das premissas normativas e fática, em casos nos quais há inclusive divergência dentre os julgadores. Aqui, por mais que queiramos, parece forçada a qualificação do caso como "fácil". Neste caso, ao que tudo indica, seria necessário enfrentar a controvérsia para que dela se tirasse algo mais do que uma posição simplesmente derivada de autoridade e, diante da ausência de uma autoridade superior claramente identificada, da prevalência numérica de uma posição majoritária. Dito de outro modo: ainda que tenhamos uma posição cética sobre a racionalidade das decisões judiciais, parece bastante óbvio que enfrentar a divergência é uma conduta desejável como guia para os casos futuros. Não fazê-lo é dar pouca importância ao dever de fundamentação das decisões judiciais, é sinalizar que o tribunal decide deste modo porque aquele conjunto de pessoas, circunstancialmente escolhidas e decidindo, assim o quis.

De outra parte, se voltamos o olhar para um caso como o do reconhecimento da união homoafetiva, parece evidente que a extensa argumentação do acórdão e a profusão de doutrinadores, nacionais e estrangeiros, citações de legislação e de jurisprudência estrangeiras, floreios retóricos e arroubos poéticos não servem ao razoável propósito de esclarecer aos jurisdicionados por que o tribunal, apesar de o texto constitucional mencionar união estável entre o homem e a mulher, achou possível reconhecer a união de casais homoafetivos. Ao invés da escassez de argumentos, a outra metade do paradoxo mencionado aparece aqui como um paroxismo 
de razões. São tantas as razões que ao final já não somos capazes de resumi-las em um conjunto coerente e devemos fazer um esforço interpretativo hercúleo para dizer que, ao fim e ao cabo, a decisão foi tomada invocando-se, por exemplo, a dignidade da pessoa humana, a liberdade ou a igualdade. O resultado final, apesar da aparente abundância de fundamentação, parece ser o mesmo: sabemos o que o tribunal decidiu, mas temos sérias dificuldades em mostrar como se fundamenta a decisão e, mais do que isso, que consequências ela acarreta para outros casos futuros.

A ilustração que ambos os casos podem nos dar aponta para uma imagem da função judicial nos tribunais superiores que aposta nos aspectos autoritativos da função, pelos quais o julgador se sente autorizado a expressar, em suas decisões, mais a sua opinião (e os seus autores preferidos, sejam eles juristas ou não) do que esclarecer, de modo claro e compreensível, as razões de sua decisão. Dados os constrangimentos institucionais que já discutimos no item anterior, o formato da decisão revela mais do que seria de se supor à primeira vista: um somatório de opiniões e posições sobre o que a legislação ou a constituição querem dizer. O julgador é, aqui, alguém escolhido pela sua erudição e pela sua capacidade técnica, que deve, a cada momento enfatizar estas características e demonstrar a sua individualidade.

Poder-se-ia resumir esta primeira parte da análise apontando para um baixo comprometimento institucional e um excessivo apego à construção de uma imagem pública do julgador, possivelmente ampliada pela sua constante exposição midiática, especialmente nos "grandes" casos, acompanhados e discutidos pela imprensa e em alguma medida pelo público, por intermédio de sessões televisionadas. Se a superexposição midiática pode funcionar como uma explicação para essa exacerbação do indivíduo diante da instituição - do ministro diante do tribunal - é de se ressaltar uma vez mais que não é apenas nos "grandes" casos que isso acontece. Seria fácil, parece-nos, culpar a TV Justiça ou a mídia e o seu interesse pelos "grandes" casos, pelas características apontadas. Pelo contrário, como discutimos acima, a análise feita das decisões sobre a aplicação da medida de segurança, casos nada midiáticos ou merecedores da atenção dos próprios juristas, parece confirmar que cada um dos ministros do STJ vota "de acordo com a sua consciência" e assim produz uma situação de incoerência jurisprudencial absolutamente chocante. Resta ao recorrente esperar que o seu pedido venha examinado pelo relator cuja posição seja a menos gravosa para o seu pedido. Significa dizer, ademais, que aparentemente as razões de recurso apresentadas pelos advogados, numa tentativa de convencimento racional, pouco efeito produzem.

Certamente poderíamos encontrar inúmeros condicionamentos práticos e institucionais que sirvam de explicação a essa realidade. Ao invés de culparmos a TV Justiça e a mídia poderíamos dizer que o modo pelo qual são selecionados os ocupantes dos cargos do primeiro escalão do Judiciário é que representa o grande nó górdio a ser desfeito. Poderíamos discutir o sistema processual e a sua abundância de oportunidades para que um caso seja 
levado ao STF ou ao STJ. Talvez devêssemos incluir nesse rol um anátema à Constituição Federal e seu extenso rol de direitos.

É verdade também que citar doutrina não é um mal em si mesmo, tampouco o é fazer um discurso fortemente ancorado em artifícios retóricos voltados à produção da emoção $0^{27}$. É um fato, contudo, que decisões demasiado longas, pouco compreensíveis, nas quais a doutrina é utilizada como apelo à autoridade e como demonstração de erudição, pouco contribuem para a construção de um Judiciário à altura dos textos normativos, inclusive constitucionais, que afirmam a obrigatoriedade de fundamentação das decisões como mecanismo de controle da atividade judicial em um Estado de Direito.

De algum modo, parece-nos que a explicação não deve ser buscada em um destes elementos isoladamente, mas em uma conjugação deles. Articulados, esses elementos apontam para uma constatação necessária se queremos entender, de fato, que uma forma de argumentar não nasce de opções pessoais de qualquer ministro mas também não deixa de ser influenciada pelo tipo de ministro que temos.

Refletindo sobre o que acabamos de mencionar, pode-se dizer que essa forma de redigir uma decisão judicial não é uma casualidade ou a mera expressão de idiossincrasias individuais dos ministros. Creio que, em maior ou menor medida, segundo os perfis individuais, ela revela uma arraigada convicção de que a função judicial, especialmente nos tribunais superiores, é aquela de expressar as opiniões e até mesmo as preferências valorativas dos ministros, servindo à construção de sua imagem pública mais do que ao esclarecimento das razões de decidir. Por detrás dela, é razoável supor que há uma concepção do Direito que privilegia os aspectos autoritativos aos normativos. De modo direto, parece-nos que os ministros expressam nas sentenças aquilo que acreditam seja o Direito de seu ponto de vista e fundamentam as suas decisões muito mais em razão de sua preferência do que levados por um compromisso com os textos normativos. Temos, portanto, uma visão personalista da função judicial e uma concepção de Direito que aposta na autoridade da decisão mais do que na sua correção.

Se essa constatação se impõe, devemos, para avançar em nossa reflexão, procurar compreender agora que papel desempenha uma constante invocação, aqui e acolá nas decisões, de padrões teóricos que requerem um

\footnotetext{
${ }^{27}$ Uma provocação histórica, feita por José Murilo de Carvalho poderia ser útil aqui: a nossa "retoriquice" não começou com a Constituição de 1988, com a maior disseminação do conhecimento da legislação, da doutrina e da jurisprudência estrangeiras ou com a existência da TV Justiça. Veja-se, a respeito, o texto: "De qualquer modo, este traç, do estilo, ou da retórica portuguesa, transferiu-se para o Brasil e talvez ainda esteja presente até hoje.Trocando-se os poetas Marcial e Juvenal por outros nomes, a observaça ${ }^{\circ}$ de Verney continuaria válida. O que se sugere aqui é que o feno `meno onipresente da citaça`o de autores estrangeiros, e da concomitante importaça o de idéias, na`o seja visto apenas como indicador de depende`ncia intelectual, nem como colocaça o correta ou incorreta de idéias. Sugere-se que uma chave útil de leitura pode ser dada pelo estilo de raciocínio. Dentro da tradiça o o brasileira, o argumento de autoridade era um requisito indispensável, era um recurso de argumentaça o, uma retórica. Em princípio, portanto, a citaça o de um autor estrangeiro na“o significava necessariamente adesa o a suas idéias, embora pudesse significar." CARVALHO, 2000, p. 143.
} 
outro tipo de atitude judicial. Se acreditarmos no que dizem muitas das decisões dos nossos tribunais eles estão, nada mais, nada menos, do que aplicando o bom standard da teoria do Direito pós-positivista, esgrimindo com suposta maestria textos de Dworkin e a célebre fórmula da ponderação de Alexy para garantir direitos e ampliar as condições de proteção da cidadania. Atuam a partir de uma condição de legitimação argumentativa para afastar a posição do legislador infraconstitucional, por exemplo, invocando a capacidade racional de um tribunal para funcionar como um mecanismo de proteção contramajoritário ou a noção de representação argumentativa ${ }^{28}$. Aparentemente, portanto, esses autores e suas concepções do Direito estão por detrás da forma como pensam e argumentam nossos julgadores.

Sem entrar aqui em uma complexa discussão sobre a recepção desses autores no Brasil ou sobre o que é e o que poderia ser uma teoria do direito pós-positivista, me parece possível afirmar que há um visível descompasso entre a postura adotada e as responsabilidades que ambos os autores reconhecem e recomendam à função judicial. Fossem genuinamente dworkinianos ou alexyanos, muito maior cuidado argumentativo, de reconstrução de precedentes e de apresentação clara das razões de decidir teria de ser tomado. De algum modo, portanto, a cúpula de nosso Judiciário lê e usa desses autores aquilo que the convém e somente aquilo que lhe convém...

Evidentemente não se espera e nem se deseja de um tribunal, sobretudo de um tribunal constitucional, fidelidade a um autor ou a uma escola e o argumento não vai nessa direção. $O$ apontamento importante, aqui, é o de que talvez estejamos diante de mais do que um olhar superficial possa relevar. Talvez possamos dizer que por debaixo dessa forma de raciocínio e de sua expressão nas decisões há um conjunto de razões mais complexas, vinculadas à repartição do poder e ao seu uso no contexto do Estado brasileiro e manejadas a partir de um discurso que, ao mesmo tempo em que sugere o respeito aos parâmetros do Estado de Direito, manipula os conceitos de modo a permitir um fortalecimento do Judiciário no confronto com outros poderes. Paradoxalmente, portanto, uma teoria do direito e dentro dela, uma teoria da argumentação com fortes pretensões racionalistas, são usadas a favor de um exercício de poder que não combina com a idéia de afirmação de direitos, construção da cidadania ou Estado de Direito.

Esse cenário, no qual, como vimos, teorias são manejadas e uma forma argumentativa é concebida e vem diuturnamente utilizada parecem remeter à formação histórica de uma cultura jurídica com fortes elementos retóricos e personalistas, cujas raízes seria interessante inventariar. Talvez o olhar da história das instituições e da

\footnotetext{
${ }^{28}$ Apenas para ficar no horizonte das decisões que já discutimos, veja-se a seguinte passagem do voto do Ministro Gilmar Mendes na ADI 4277: "Volto a citar uma passagem já citada por mim quando discutimos o caso das células-tronco, uma passagem, a meu ver, muito expressiva do jusfilósofo e constitucionalista Robert Alexy, quando diz que o parlamento representa o cidada o politicamente, o Tribunal Constitucional o representa argumentativamente”. BRASIL. 2011. Supremo Tribunal Federal. Ação Direta de Inconstitucionalidade No 4277. Inteiro Teor do Acórdão. Relator: Min. Ayres Britto. Consulta em 05/04/2012. Disponível em: http://www.stf.jus.br/portal/geral/verPdfPaginado.asp?id=400547\&tipo=TP\&descricao=ADI\%2F4277, p. 749.
} vol. 08, nº. 04, Número Especial. Rio de Janeiro, 2015. pp. 2517-2531 
história do pensamento jurídico brasileiro possa nos auxiliar a compreender esse curioso paradoxo por intermédio do qual a cidadania brasileira vê direitos serem atribuídos, reconstruídos e ressignificados por meio de decisões cujo controle é, senão impossível, de difícil alcance.

Um outro aspecto bastante interessante a ser verificado em continuidade à investigação já realizada é o do papel efetivo do uso de decisões judiciais de tribunais estrangeiros, assim como a de autores estrangeiros. Como constatamos, há uma grande profusão de referencias, cujo caráter, à primeira vista, parece ser o de reforço retórico, como apelo à autoridade. Necessária, no entanto, uma verificação mais cuidadosa para avaliar se estamos diante de uma circulação de modelos jurídicos, com a incorporação de conceitos, procedimentos e práticas argumentativas, ou se realmente se trata de uma invocação puramente retórica.

\title{
BETWEEN THE REASONS PAROXYSM AND NO REASON: PARADOXES OF A LEGAL PRACTICE
}

\begin{abstract}
An analysis of judgments of Brazilian higher courts indicates a sharp deficit of rationality in the justifications produced by the judges as to the reasons for their decisions, used the theoretical instruments of the Theory of Legal Argumentation. There is a remarkable difficulty in clearly establishing the link between the decision and its reasons as well as to relate it to other elements of the legal system (general rules and jurisprudence standards). Historical and institutional conditionings can serve as plausible explanations for this situation and this article seeks to explore, albeit in initial mode, some explanatory hypotheses of Brazilian argumentative practice setting.
\end{abstract}

Keywords: judicial argumentation - higher courts - the theory of legal argument - rationality

\section{REFERÊNCIAS DAS FONTES CITADAS}

ATIENZA, Manuel. As Razões do Direito: Teorias da Argumentação Jurídica. Tradução de Maria Cristina G. Cupertino. 2. ed. São Paulo: Landy, 2002.

ATIENZA, Manuel. Curso de Argumentación Jurídica. Madrid: Trotta, 2013.

BRASIL. 2010. Supremo Tribunal Federal. Arguiição de Descumprimento de Preceito Fundamental no. 153. Inteiro Teor do Acórda o. Relator: Min. Eros Grau. Consulta em 03/08/2011. Disponível em: http://redir.stf.jus.br/paginadorpub/paginador.jsp? docTP=AC\&docID=612960.

BRASIL. 2011. Supremo Tribunal Federal. Ação Direta de Inconstitucionalidade No 4277. Inteiro Teor do Acórdão. Relator: Min. Ayres Britto. Consulta em 05/04/2012. Disponível em: http://www.stf.jus.br/portal/geral/verPdfPaginado.asp?id=400547\&tipo=TP\&descricao=ADI\%2F4277 2012. Superior Tribunal de Justiça. Recurso Especial nº 1.111.566/DF. Inteiro Teor do Acórdão. Relator: Min. Marco Aurélio Bellize. Acesso em 08/07/2013. Disponível em: 
https://ww2.sti.jus.br/processo/jsp/revista/abreDocumento.jsp?componente=ITA\&sequencial=11 14564\&nu m_registro $=200900250862 \&$ data $=20120904 \&$ formato $=P D F$.

BRAVO, Omar Alejandro. As prisões da loucura, a loucura das prisões: a (des)construção institucional do preso psiquiátrico. Tese (Doutorado em Psicologia). Instituto de Psicologia, Universidade de Brasília, Brasília, 2004. $221 \mathrm{p}$.

CARVALHO, José Murilo de. História Intelectual no Brasil: a Retórica como Chave de Leitura. Topoi, Rio de Janeiro, n. 1, p. 123-152, jan-dez 2000.

CHAIM, Caio C. A Relação entre Legislativo e Judiciário na dinâmica democrática: Análise do caso da Lei Seca sob o viés argumentativo-principiológico. Relatório de Pesquisa de Iniciação Científica 2012-2013.. Programa de Iniciação Científica CNPq/UnB.

MACCORMICK, Neil. Retórica e o estado de direito. Trad. Conrado Hübner Mendes e Marcos Paulo Veríssimo. Rio de Janeiro: Elsevier, 2008.

MOREIRA, Larissa Learth. Análise do Julgamento do caso Ficha Limpa sob o viés Argumentativo e Principiológico. Relatório de Pesquisa de Iniciação Científica 2011-2012. Programa de Iniciação Científica $\mathrm{CNPq} / \mathrm{UnB}$.

ROESLER, Claudia R.; SENRA, Laura Carneiro de Mello. Lei de Anistia e Justiça de Transição: a releitura da ADPF 153 sob o vies argumentativo-principiológico. Sequência, volume 64, p. 131-160, 2012. Disponível em: periodicos.ufsc.br/index.php/sequencia/article/view/2177-7055.2012v33n64p131.

ROESLER, Claudia R; LAGE, Leonardo. A argumentação do Supremo Tribunal Federal e do Superior Tribunal de Justiça acerca da periculosidade de agentes inimputáveis e semi-imputáveis. Revista Brasileira de Ciências Criminais, ano 21, n. 104, set./out., 2013, p. 347-389.

ROESLER, Claudia R; SENRA, Laura Carneiro de Mello. Gênero e Justiça de Transição no Brasil. Revista Jurídica da Presidência, vol. 15, n. 105, fev./mai 2013, p. 35-67. Disponível em: www4.planalto.gov.br/revistajuridica/vol-15-n-105-edicao-especial-fev-mai-2013/menu-

vertical/apresentacao/rjp-105.pdf

ROESLER, Claudia R; SANTOS, Paulo Alves. Argumentação jurídica utilizada pelos tribunais brasileiros ao tratar das uniões homoafetivas. Revista Direito GV, 10(2), p. 615-638, jul-dez 2014.

TOULMIN, Stephen E. Os usos do argumento. Trad. Reinaldo Guarany. 2. ed. São Paulo: Martins Fontes, 2006.

Trabalho enviado em 02 de agosto de 2015.

Aceito em 07 de outubro de 2015. 